\title{
Correlation between nasopharyngoscopy and cephalometry in the diagnosis of hyperplasia of the pharyngeal tonsils
}

\section{Correlação entre a nasofibrofaringoscopia e a cefalometria no diagnóstico de hiperplasia de tonsilas faríngeas}

\author{
Rodrigo Agne Ritzel', Luana Cristina Berwig², Ana Maria Toniolo da Silva ${ }^{3}$, Eliane Castilhos Rodrigues Corrêa4, \\ Eliane Oliveira Serpa 5 .
}

1) Master. Otolaryngologist from Hospital Universitário de Santa Maria - Santa Maria University Hospital.

2) Master. Resident Speech Therapist for Multidisciplinary Integrated Management and Health Care Residency Program from Universidade Federal de Santa Maria Federal University at Santa Maria.

3) Doctor. Professor Member from Speech Therapy Course of Universidade Federal de Santa Maria/ Federal University of Santa Maria.

4) Doctor. Adjunct Professor of Physical Therapy Course of Universidade Federal de Santa Maria/ Federal University of Santa Maria.

5) Master. Orthodontics Clinical.

Institution: Federal University of Santa Maria.

Santa Maria / RS - Brazil.

Mailing address: Rodrigo Agne Ritzel - Pinheiro Machado Street, 2350/806 - Bairro Centro - Santa Maria / RS - Brazil - Zip-code: 97050-600 - Telephone: (+55 55) 3028-9507 - E-mail: rodrigoritzel@ymail.com

Article received in August 17, 2011. Article approved in February 6, 2012.

\section{SUMMARY}

Introduction: Hyperplasia of the pharyngeal tonsil is one of the main causes of mouth breathing, and accurate diagnosis of this alteration is important for proper therapeutic planning. Therefore, studies have been conducted in order to provide information regarding the procedures that can be used for the diagnosis of pharyngeal obstruction.

Objective: To verify the correlation between nasopharyngoscopy and cephalometric examinations in the diagnosis of pharyngeal tonsil hyperplasia.

Method: This was a cross-sectional, clinical, experimental, and quantitative study. Fifty-five children took part in this study, 30 girls and 25 boys, aged between 7 and 11 years. The children underwent nasofibropharyngoscopic and cephalometric evaluation to determine the grade of nasopharyngeal obstruction. The Spearman's rank correlation coefficient at the $5 \%$ significance level was used to verify the correlation between these exams.

Results: In the nasopharyngoscopy evaluation, most children showed grade 2 and 3 hyperplasia of the pharyngeal tonsil, which was followed by grade 1 . In the cephalometry assessment, most children showed grade 1 hyperplasia of the pharyngeal tonsil, which was followed by grade 2 . A statistically significant regular positive correlation was observed between the exams.

Conclusion: It was concluded that the evaluation of the pharyngeal tonsil hyperplasia could be carried out by fiber optic nasopharyngoscopy and cephalometry, as these examinations were regularly correlated. However, it was found that cephalometry tended to underestimate the size of the pharyngeal tonsil relative to nasopharyngoscopy.

Keywords: mouth breathing, nasopharynx, diagnosis, comparative study.
RESUMO

Introdução: A hiperplasia de tonsila faríngea é uma das principais causas da respiração oral. O diagnóstico preciso desta alteração é importante para o correto planejamento terapêutico. Em vista disso, estudos têm sido desenvolvidos a fim de fornecer subsídios quanto aos procedimentos que podem ser utilizados para o diagnóstico de obstrução faríngea.

Objetivo: Verificar a correlação entre os exames de nasofibrofaringoscopia e cefalometria no diagnóstico de hiperplasia de tonsila faríngea.

Método: Estudo transversal, clínico e experimental. Participaram deste estudo 55 crianças, 30 meninas e 25 meninos, com idades entre 7 e 11 anos. As crianças foram submetidas à avaliação nasofibrofaringoscópica e cefalométrica para a determinação do grau de obstrução da nasofaringe. Para verificar a correlação entre esses exames foi utilizado o coeficiente de correlação de Spearman ao nível de significância de $5 \%$.

Resultados: Na nasofibrofaringoscopia a maioria das crianças apresentou hiperplasia de tonsila faríngea graus 2 e 3, seguidas de grau 1. Na cefalometria a maior parte das crianças apresentou hiperplasia de tonsilas faríngeas grau 1, seguida de grau 2. Na correlação entre os exames, evidenciou-se correlação regular e positiva.

Conclusão: A avaliação da hiperplasia de tonsilas faríngeas pode ser realizada pela nasofibrofaringoscopia e pela cefalometria, pois estes exames apresentam uma relação regular e positiva. No entanto, verificou-se que a cefalometria tende a subestimar o tamanho da tonsila faríngea em relação à nasofibrofaringoscopia.

Palavras-chave: respiração bucal, nasofaringe, diagnóstico, estudo comparativo. 


\section{INTRODUCTION}

The breathing process, which begins at the upper airway and culminates in gas exchange inside the alveoli, is essential for the human organism to survive. When breathing begins through the nose, the air is prepared in order to reach the lungs with the ideal conditions, that is, warmed, moistened, and filtered, thus activating immunological processes such as mucociliary transport and microbicidal activity that protect the lower airway. When breathing begins through the mouth, despite air warming and moistening, no filtering or immunological activity occurs (1).

When mouth breathing occurs in childhood, a period during which intense facial muscular and skeletal growth occurs, it promotes a pathological adaptation of the structures of the stomatognathic system, to the detriment of the usually harmonious morphological and functional growth of these structures (2).

The main causes of mouth breathing in childhood are the hypertrophy of the pharyngeal and/or palatine tonsil, nasal mucosa and turbinate edema, nasal septal deviation, extended suction habits, and others (3).

Morphological adaptations in mouth-breathing children occur with the aim of facilitating the necessary arrival of the air to the alveoli. Thus, it is possible to observe maxillary hypoplasia and posterior mandibular demotion/ rotation, which lead to dental occlusion alterations, higher mandibular inclination, and a vertical facial growth pattern, with alterations in normal facial proportions and hard palate elevation, head anteriorization, and muscular deharmonization, occurring mainly in the nasofacial region. These adaptations generate functional changes in the stomatognathic system, which are observed through alterations in speech, chewing, and deglutition $(4,6)$.

The complexity of the consequences of mouth breathing that are associated with various etiologies justifies the participation of several professionals, including otorhinolaryngologists, odontologists, phonoaudiologists, physiotherapists, pediatricians, among others, along the different phases of the care of mouth-breathers, including the diagnosis, treatment, rehabilitation, and the prevention of mouth breathing in childhood. Multidisciplinary staff integration is essential, as it is desirable to use a uniform categorization of mouth breathers, consisting of the same terminology and the same complementary exams.

Accurate diagnosis of the cause of mouth breathing is essential to the effectiveness of treatment. In phonoaudiology, the type of care that is used for mouthbreathing patients is typically determined by the etiology of the altered respiratory mode. Therefore, the accurate use of the available diagnostic options contributes to early diagnosis, and will aid in the establishment of a multidisciplinary therapeutics that are more appropriate to each case and minimize relapse during mouth breathing rehabilitation $(7,8)$.

Most causes of mouth breathing are diagnosed through a disarmed otorhinolaryngologic exam, except for the diagnosis of hyperplasia of the pharyngeal tonsils, which demands that complementary exams be used (3).

In the diagnosis of pharyngeal hyperplasia, the exams that are typically requested include cavum radiography and nasopharyngoscopy. Nasopharyngoscopy is a procedure that is used to visualize the pharyngeal tonsil and its relation to other nasopharyngeal structures, and is considered by many authors as the most reliable exam in the diagnosis of nasopharyngeal obstruction (9-13). Cephalometry is an exam that is similar to cavum radiography; however, it is carried out through the use of a cephalostat, which enables the most appropriate patient positioning, and provides data related to craniofacial growth and the myofunctional status of these structures (14). Since it is a noninvasive exam, it is more comfortable for the patient, and is often more accepted by children. Moreover, is associated with a lower cost and greater availability relative to nasopharyngoscopy.

With the aim of contributing to the accurate diagnosis of mouth breathing, this study was carried out with the purpose of verifying the correlation between nasopharyngoscopy and cephalometry in the diagnosis of hyperplasia of the pharyngeal tonsils.

\section{METHOD}

The preset study was approved by the Research Ethics Committee of the institution of origin under the protocol number 220.0.243.000-8. The children agreed to take part in the study and the Informed Consent forms were signed by their representatives.

The study sample consisted of children from 3 public schools who were evaluated from September 2008 through December 2009. The inclusion criteria were included complaints related to mouth breathing, such as night drooling, snoring, and restless sleep; the group age ranged from 7.0 to 11.11 years. Children that presented evident neurological disorders, craniofacial malformation, syndromes, or history of pharyngeal surgery were excluded from the study. Sex differences were not taken into account.

After employing the inclusion and exclusion criteria, 55 
children, including 25 males and 30 females, with an average age 9.8 years were selected. These children underwent otorhinolaryngologicassessment, aswellas nasopharyngoscopy and cephalometry to check for the presence or absence of nasopharyngeal obstruction. Any other causes of obstruction of the upper airway, such as nasal septal deviation, primary hypertrophy of the nasal turbinates, polyps, and malformations were not diagnosed in the study sample. For the patients with bacterial rhinosinusitis and/or symptomatic allergic rhinitis, appropriate treatments were prescribed and subsequent revaluation was carried out during a period ranging from 30 to 60 days. After this period was completed, the nasopharyngoscopy and cephalometry exams were performed.

Otorhinolaryngologic evaluation was carried out in the presence of and with the help of the parents or sponsors. After a general and specific otorhinolaryngologic anamnesis was conducted, giving emphasis to the aspects related to mouth/nasal breathing, a physical exam consisting of otoscopy, anterior rhinoscopy, cervical palpation, and nasoscopy was carried out. This evaluation allowed for the determination of whether the patient had either an oral or mouth-breathing mode.
Immediately after the completion of the anamnesis and the otorhinolaryngologic clinical exam, nasopharyngoscopy was carried out, always by the same assessor and in the same environment, employing topical anesthesia (lidocaine 5\%) and a nasal vasoconstrictor (oxymetazoline 0.05\%), with a flexible nasofibroscope $\left(3.2 \mathrm{~mm}\right.$ Mashida ${ }^{\circledR}$ brand, microcamera Asap ${ }^{\circledR}$ ), and recorded on DVD. Through this exam, apart from studying the size and the relation of the pharyngeal tonsil to the nasopharynx, the nasal septum positioning, turbinate size, upper pole of the palatine tonsils, presence of secretions, and other kinds of lesions in the nasal cavity and hypopharynx were assessed.

When using nasopharyngoscopy to determine the level of hyperplasia of the pharyngeal tonsils, we used a graded scale in which the relation of the pharyngeal tonsils to the other structures that are present in the nasopharynx was assessed (15), as follows:

- Grade 1-tonsil without contact with the nasopharyngeal structures (Figure 1);

- Grade 2-tonsil in contact with the torus tubarius(Figure 2);

- Grade 3-tonsil in contact with the torus tubarius and vomer (Figure 3);
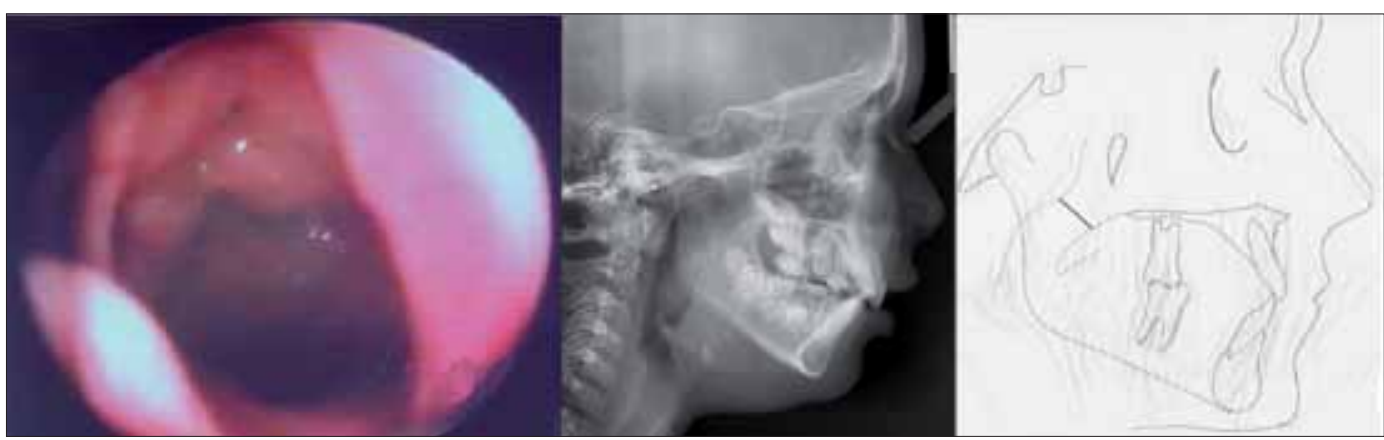

Figure 1. Grade 1 hyperplasia of the pharyngeal tonsils by nasofibropharyngoscopy and cephalometry (cephalometric analysis).
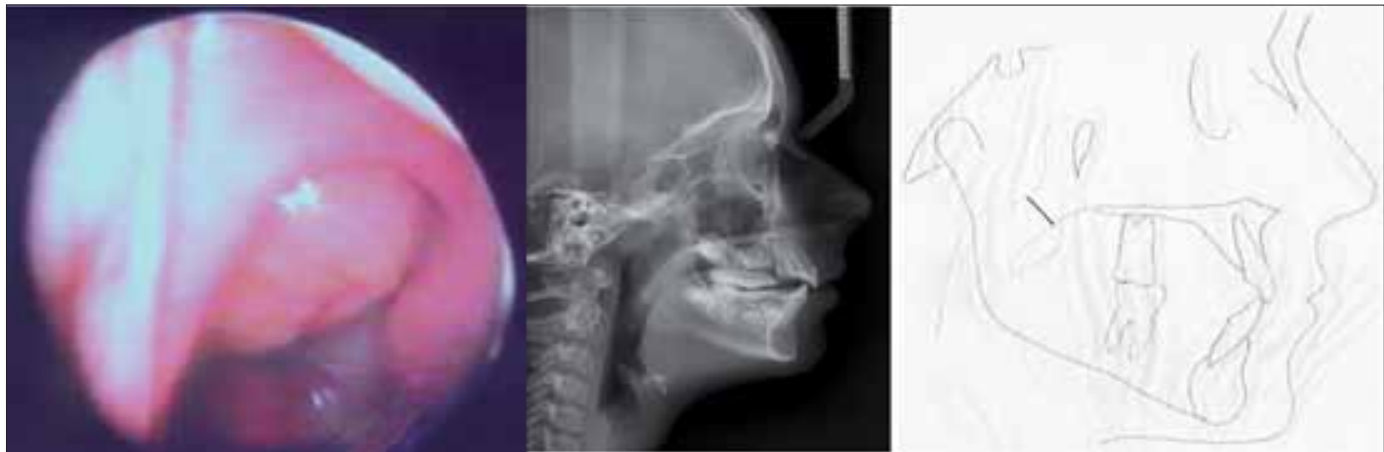

Figure 2. Grade 2 hyperplasia of the pharyngeal tonsils by nasofibropharyngoscopy and cephalometry (cephalometric analysis). 


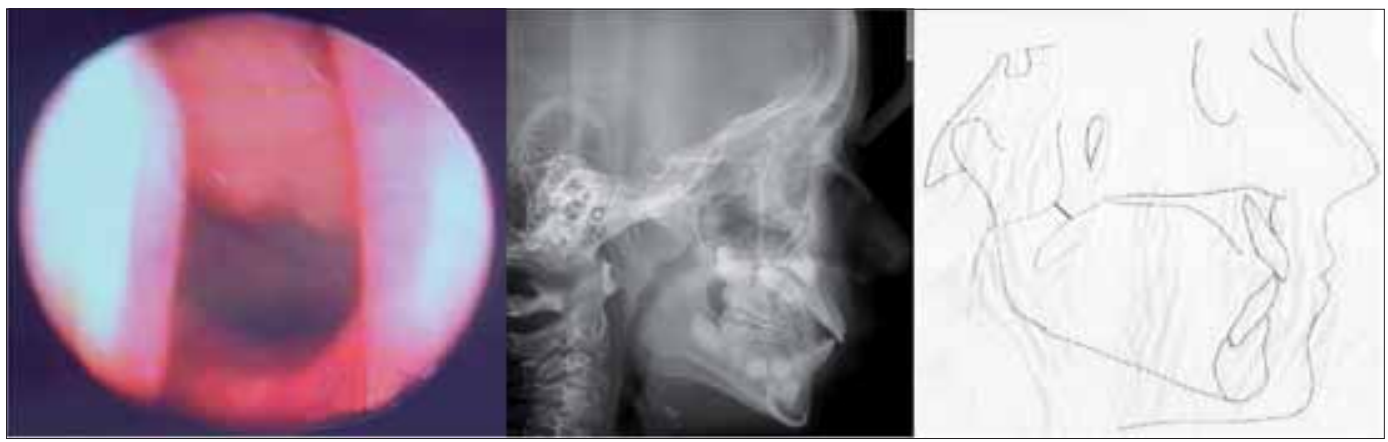

Figure 3. Grade 3 hyperplasia of the pharyngeal tonsils by nasofibropharyngoscopy and cephalometry (cephalometric analysis).

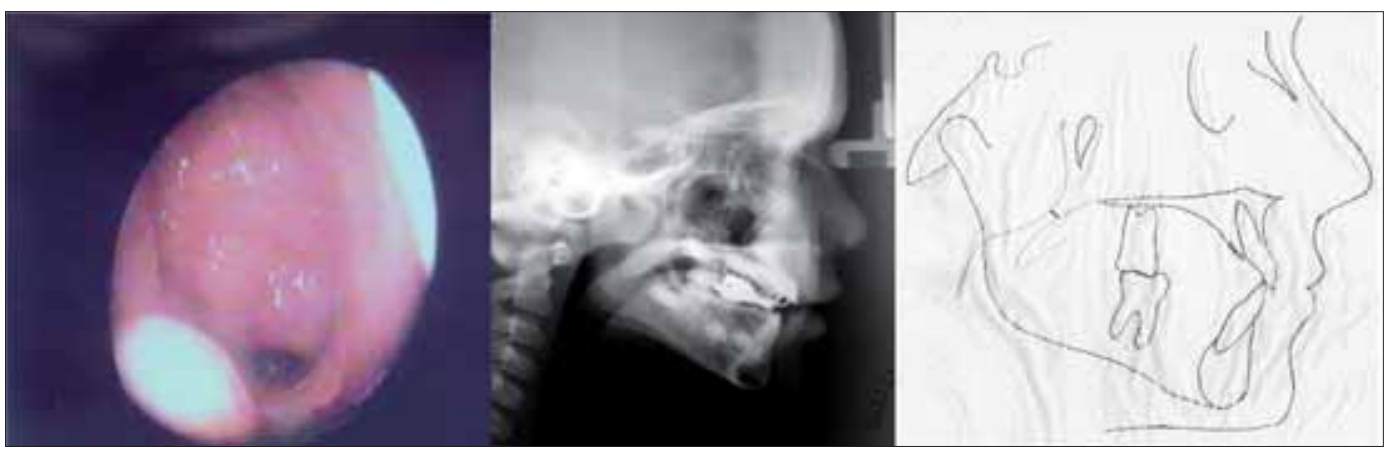

Figure 4. Grade 4 hyperplasia of the pharyngeal tonsils by nasofibropharyngoscopy and cephalometry (cephalometric analysis)

- Grade 4 - tonsil in contact with the torus tubarius, vomer, and the soft palate at rest (Figure 4).

Subsequently, children were referred to the odontological radiology service center to undergo a cephalometric assessment, through which it was possible to obtain a left profile cranium teleradiograph by using the cephalostat for positioning the patient at a distance of 1.5 meters. For the standard lateral radiography assessment, computerized cephalometric tracing was performed with Cef X software (a computerized cephalometry system version 2.4.0.0 from CDT software for informatics consulting, development, and training). The exam was carried out with the same equipment in each patient, and was analyzed by the same professional expert in odontological radiology.

When using cephalometric analysis, in order to determine the level of hyperplasia of the pharyngeal tonsils, we used a graded scale in which the airway between the palate pharynx border and the point that was most proximal to the pharynx was measured in millimeters (16), as follows:

- Grade 1 - nasopharyngeal space larger than $6 \mathrm{~mm}$ (Figure 1);
- Grade 2 - nasopharyngeal space between 4.1 and 6 mm (Figure 2);

- Grade 3 - nasopharyngeal space between 2.1 and 4 mm (Figure 3);

- Grade 4-nasopharyngeal space between 0 and $2 \mathrm{~mm}$ (Figure 4).

In order to verify the correlation between the nasopharyngoscopy and cephalometry examinations, the Spearman's rank correlation test was performed at a significance level of $5 \%$. The test results in a correlation coefficient ranging from -1 to +1 , with zero indicating that there is no correlation, -1 indicating a perfect negative correlation, and +1 denoting a perfect positive correlation; the closer to 1 or +1 , the greater the correlation between the variables that are being tested. The possible results for a positive correlation are (17):

- 0 when there is no correlation;

- Between 0 and 0.3 - poor correlation;

- Between 0.3 and 0.6 - regular correlation;

- Between 0.6 and 0.9 - a very strong correlation;

- Equal to 1 - a perfect correlation between the data.

For calculating the sensitivity, specificity, the positive 
predictive value, and the negative predictive value of radiologic exams, nasopharyngoscopy was considered to be the reference exam (the gold standard). It was also necessary to establish limit values in order to determine whether the exams that were studied were either positive or negative. Therefore, the grade 1 and 2 nasopharyngoscopic and cephalometric exams were considered to be negative, and the grade 3 and 4 exams were considered to be positive.

\section{RESULTS}

Table 1 shows the results of the correlation analysis between the nasopharyngoscopy and cephalometry examinations in diagnosing the grade of hyperplasia in the pharyngeal tonsils.

From the analysis of the results presented in Table 1 , it was possible to verify that the Spearman's rank correlation coefficient, Rho (R), was equal to 0.52 . This result indicates a significant regular and positive association between the nasopharyngoscopy and cephalometry assessments $(p=0.000)$ at a significance level of $5 \%$.

Table 2 describes the nasopharyngoscopy and cephalometry distribution results that were used for assessing the diagnostic tests.

In Table 2, using nasopharyngoscopy as the gold standard for the diagnosis of hyperplasia of the pharyngeal tonsils, it was possible to verify that the sensitivity of cephalometry (determined by the proportion between the number of correct positive radiographic cephalometry diagnoses and the total number of positive cases) was $35 \%$. The negative predictive value of cephalometry (determined by the proportion between the number of correct negative diagnoses and the total number of negative cases) was $97 \%$. The positive predictive value of the cephalometric exam (determined by the ratio of the number of correct positive cephalometric diagnoses and the total number of positive cephalometric diagnoses) was found to be $87 \%$. The negative predictive value (determined by the ratio of the number of correct negative cephalometric diagnoses and the total number of negative cephalometric diagnoses) was $72 \%$.

\section{DisCUSSION}

Hyperplasia of the pharyngeal tonsils is one of the main causes of upper airway obstruction. For this reason, studies have been carried out with the objective of assessing the reliability of the available diagnostic procedures that are used for the detection of nasopharyngeal obstruction
Table I. Correlation between the nasopharyngoscopy and cephalometry examinations for the diagnosis of the grade of hypertrophy of the pharyngeal tonsils.

\begin{tabular}{lccc}
\hline Exam & $\begin{array}{c}\text { Nasopha- } \\
\text { ryngoscopy }\end{array}$ & Cephalometry & \\
\hline Gradtuction & $\mathrm{n}=15$ & $\mathrm{n}=32$ & \\
& $27.27 \%$ & $58.18 \%$ & \\
Grade2 & $\mathrm{n}=20$ & $\mathrm{n}=15$ & $\mathrm{R}=0.52$ \\
& $36.36 \%$ & $27.27 \%$ & $\mathrm{p}=0.000$ \\
Grade3 & $\mathrm{n}=19$ & $\mathrm{n}=5$ & \\
& $34.54 \%$ & $9.09 \%$ & \\
Grade 4 & $\mathrm{n}=1$ & $\mathrm{n}=3$ & \\
& $1.83 \%$ & $5.46 \%$ & \\
\hline
\end{tabular}

$\mathrm{N}=$ number of children; $\mathrm{p}=$ significance level at $5 \% ; \mathrm{R}=$ Spearman's rank correlation coefficient.

Table 2. Distribution of children according to the results in nasopharyngeal and cephalometric exams.

\begin{tabular}{lccc}
\hline \multirow{2}{*}{ Cephalometry } & \multicolumn{2}{c}{ Nasopharyngoscopy } & Total \\
& Positive & Negative & \\
\hline Positive & 7 & I & 8 \\
Negative & 13 & 34 & 47 \\
\hline Total & 20 & 35 & 55 \\
\hline
\end{tabular}

resulting from the increased size of the pharyngeal tonsils. The most commonly used exams are cavum radiographs, flexible and rigid nasopharyngoscopy, and cephalometry $(11,13,18)$.

Reports in the literature indicate that there is concern regarding the best method for diagnosing and treating children in which hyperplasia of pharyngeal tonsils is suspected, which a frequently occurring situation in the otorhinolaryngological practice $(13,19)$. Therefore, this study aimed to establish a correlation between the nasopharyngoscopy and cephalometry examinations in the diagnosis of hyperplasia of the pharyngeal tonsils, while highlighting their main contributions.

The findings of this study demonstrated that it was possible to verify a regular and positive correlation, $\mathrm{R}=$ 0.52; however, a perfect correlation between the exams was not found. The results revealed that most of the children showed grade 2 and 3 hyperplasia of the pharyngeal tonsils, followed by grade 1 in the nasopharyngoscopic exam, and most of the children showed grade 1 hyperplasia of the pharyngeal tonsils, followed by grade 2 in the cephalometric assessment (Table 1). After analyzing these results, it was possible to infer that cephalometry, as compared to nasopharyngoscopy, presented a tendency 
to underestimate the pharyngeal tonsil size in the nasopharynx.

The sensitivity of cephalometric exam, which indicates the probability of a positive result when the patient presents with the condition in question, was 35\%. The negative predictive value, which expresses the probability that the individual does not present with the condition in question when the exam result is negative, was $72 \%$. These results suggested that a negative cephalometric exam might not provide a properassessment of the nasopharynx when compared to the nasopharyngoscopic exam.

Similar results were obtained when cavum radiography and flexible nasopharyngoscopy for the assessment of the grade of nasopharyngeal obstruction were compared in other similar study (13). The authors concluded that children with classical symptoms of respiratory obstruction, in the absence of hypertrophy of the pharyngeal tonsils by a radiological exam, should undergo flexible nasopharyngoscopy in order to achieve a more accurate diagnosis.

Several published studies consider nasopharyngoscopy to be the gold standard exam for assessing the nasopharynx $(12,13,20-22)$. This is justified, among other reasons, by the dynamic and tridimensional nasopharyngeal view provided by this assessment, which makes it possible to analyze not only the pharyngeal tonsil size, but also its relation with other structures in the region. This may explain the reason why, in the comparison between nasopharyngoscopy and cephalometry, the latter tended to underestimate the size and position of the pharyngeal tonsils in relation to the nasopharynx.

Frequently in clinical practice, it is possible to verify that patients with mouth breathing symptoms who show normal or next to normal pharyngeal tonsil size with radiological exams, may present hyperplasia of the pharyngeal tonsils and other alterations, such as hypertrophy of the lower turbinate and posterior nasal septal deviation, when assessed by nasopharyngoscopy.

This statement is reinforced by another study (11) in which 45 children between 4 and 12 years of age were assessed with nasopharyngoscopy; all of them presented chronic nasal obstruction due to hyperplasia of the pharyngeal tonsils, and cavum radiography revealed no alterations. The results demonstrated that $27 \%$ (17 cases) of the pharyngeal tonsils were estimated to be large, $42 \%$ ( 24 cases) of the pharyngeal tonsils were of moderate size, and 31\% (19 cases) of the pharyngeal tonsils were small. Furthermore, the exams detected 8 cases of hypertrophy of the lower turbinate (13.3\%) and 4 cases of posterior nasal septal deviation (6.6\%). These findings reinforced the importance of the indication of nasopharyngoscopy for children with nasal obstruction and normal radiological exams, as this exam allows direct, tridimensional, and dynamic assessment of the cavum area.

On the other hand, another study (23) that verified the efficacy of lateral cephalometric radiography in the diagnosis of hyperplasia of the pharyngeal tonsils compared with nasal endoscopy, differs from the results of the present study, as the authors substantiated that lateral cephalometric radiography proved to be an effective exam because of its sensitivity, specificity, and high positive and negative predictive values for diagnosis. They concluded that in spite of the superiority of nasopharyngoscopy in assessing the nasopharynx, a cephalometric exam that was negative for hypertrophy of the pharyngeal tonsils would be sufficient to exclude this pathology.

Based on information that was derived from 3 units that comprise the SUS (Sistema Único de Saúde), another study reported that mouth breathing is the most frequently cited complaint and that cavum radiography was the most commonly requested exam by otorhinolaryngologists (19). From the results of the present study, it can be inferred that if only the radiographic exam is used for the detection of hyperplasia of the pharyngeal tonsils, a proper mouthbreather diagnosis and treatment might be compromised, as in some cases the grade of pharyngeal tonsil obstruction was underestimated relative to the nasopharyngoscopic exam.

When not treated in childhood, mouth breathing causes many alterations, including craniofacial, dental, and phonoarticulatory changes, as well as alterations in body posture, oral functions, sleep, nutrition, behavior, and others (24). All of these alterations that are presented by mouth breathers require multidisciplinary intervention, including physicians, phonoaudiologists, odontologists, physiotherapists, among others (1).

Although cephalometry was only regularly correlated with nasopharyngoscopy in diagnosing mouth breathing, that exam was able to complement the endoscopic exam, thus providing information regarding facial growth that could be documented and monitored. This information will be useful for other professionals involved in the care of mouth-breathing patients.

Cephalometry provides early identification of many alterations that are present in mouth-breathing patients and provides the otorhinolaryngologist with information about the nasopharynx, informs the phonoaudiologist about morphological alterations of the stomatognathic system, and informs the odontologists about facial growth 
and dental occlusion $(3,14,23)$. Therefore, cephalometry is useful not only for the initial diagnosis, but also in cost reduction and promoting collaboration between the multidisciplinary staff members that are involved in the care of mouth-breathing patients.

A research study comparing cavum radiography with cephalometry found that in the first exam $61 \%$ of the patients were incorrectly positioned (25). Importantly, the cephalostat is used in cephalometry to control the positioning of the patient, which explains the superiority of this exam compared to cavum radiography.

Although nasopharyngoscopy is the gold standard exam for nasopharyngeal assessments, cephalometry is a complementary exam that provides information about craniofacial growth, thus making it possible to document and monitor the complex morphofunctional modifications related to mouth breathing.

In this study, cephalometry showed a tendency to underestimate the size of pharyngeal tonsil compared with nasopharyngoscopy; therefore, we suggest that patients presenting with mouth-breathing symptoms and normal radiography be referred for a complementary assessment with nasopharyngoscopy, which is associated with greater diagnostic accuracy due to its tridimensional and dynamic nature.

\section{CONCLUSIONS}

Nasopharyngeal assessment of children can be performed with nasopharyngoscopy and cephalometry, as these exams are associated with a regular and positive correlation. However, we found that cephalometry tends to underestimate the size of the pharyngeal tonsil compared with nasopharyngoscopy. Therefore, nasopharyngoscopy is suggested when the cephalometry results for nasopharyngeal obstruction are negative in patients with mouth-breathing symptoms.

\section{BibLIOGRAPHIC REFERENCES}

1. Weckx LLM, Weckx MY.Respirador bucal: causas e conseqüências. Rev Bras de Medicina. 1995, 52(8):86374.

2. Lessa FCR, Enoki C, Feres MFN, Valera FCP, Lima WTA, Matsumoto MAN. Influência do padrão respiratório na morfologia craniofacial. Rev Bras Otorrinolarigol. 2005, 71(2):156-60.

3. Mocellin M, Fugmann EA, Gavazzoni FB, Ataide AL,
Ouriques FL, Herrero Jr. F. Estudo cefalométrico-radiológico e otorrinolaringológico correlacionando o grau de obstrução nasal e o padrão de crescimento facial em pacientes não tratados ortodonticamente. Rev Bras de Otorrinolarigol. 2000, 66(2):116-20.

4. Motonaga SM, Berte LC, Anselmo-Lima WT. Respiração bucal: Causas e alterações no sistema estomatognático. Rev Bras de Otorrinolarigol. 2000, 66(4):373-79.

5. Cuccia AM, Lotti M, Caradonna D. Oral breathing and head posture. Angle Orthodontist. 2008, 78(1):77-82.

6. Harari D, Redlich M, Miri S, Hamud T, Gross M. The effect of mouth breathing versus nasal breathing on dentofacial and craniofacial development in orthodontic patients. Laryngoscope. 2010, 120(10):2089-93.

7. Junqueira P. Respiração oral: considerações fonoaudiológicas. In: Junqueira P; Dauden AT. Aspectos Atuais em Terapia Fonoaudiológica II. São Paulo: Pancast; 2002, p.32-42.

8. Junqueira P. Avaliação miofuncional. In: Marchesan IQ. Fundamentos em Fonoaudiologia - Aspectos Clínicos da Motricidade Oral. $2^{\mathrm{a}}$ ed. Rio de Janeiro: Guanabara-Koogan; 2005, p.19-28.

9. Wang DY, Bernheim N, Kaufman L, Clement P. Assessment of adenoid size in children by fibreoptic examination. Clin Otolaryngol Allied Sci. 1997, 22(2):1727.

10.Monteiro ECM, Pilon RR, Dall`Oglio G, Giovanna P. Estudo da hipertrofia adenoidiana: endoscopia $\mathrm{X}$ radiografia de nasofaringe. Rev Bras Otorrinolaringol. 2000, 66(1):912.

11.Souza BB, Hennemann GV, Anselmo-Lima WT. Importance of nasal fiberotic examination in the presence of a normal x-ray of cavum. Int $J$ Pediatr Otorhinolaryngol. 2000, 55(1):29-32.

12. Mlynarek A, Tewfik MA, Hagr A, Manoukian JJ, Schloss MD, Tewfik TL etal. Lateral Neck Radiography versus Direct Video Rhinoscopy in Assessing Adenoid Size. J Otolaryngol. 2004, 33(6):360-5.

13.Lourenço EA, Lopes KC, Pontes Júnior A, Oliveira MH, Umemura A, Vargas AL. Estudo comparativo radiológico e nasofibroscópico do volume adenoideano em crianças respiradoras orais. Rev Bras Otorrinolaringol. 2005, 71(1):238.

14.Bianchini AP. A cefalometria nas alterações miofuncionais 
orais diagnóstico e tratamento fonoaudiológico. São Paulo: Pró-Fono; 2002.

15.Parikh SR, Coronel M, Lee JJ, Brown SM. Validation of a new grading system for endoscopic examination of adenoid hypertrophy. Otolaryngol Head Neck Surg. 2006, 135(5):684-7.

16. McNamara JrJA.A method of cephalometric evaluation. Am J Orthod. 1984, 86(6):449-69.

17.Callegari-Jacques SM. Bioestatística: princípios e aplicações.Porto Alegre: Artmed; 2003.

18. Chisholm EJ, Lew-Gor S, Hajioff D, Caulfield H.Adenoid size assessment: a comparison of palpation, nasendoscopy and mirror examination. Clin Otolaryngol. 2005, 30(1):3941.

19.T-Ping C, Weckx LLM. Atendimento otorrinolaringológico do Sistema Único de Saúde de crianças e adolescentes em três municípios brasileiros. Rev Bras de Otorrinolarigol. 2008, 74(4):571-8.

20. Wormald PJ, Prescott CA. Adenoids:comparison of radiological assessment methods with clinical and endoscopic findings. J Laryngol Otol. 1992, 106(4):3424 .

21. Finkelstein Y, WexlerD, Berger G, Nachmany A, ShapiroFeinberg M, Ophir D. Anatomical basis of sleep-related breathing abnormalities in children with nasal obstruction. Arch Otolaryngol Head Neck Surg. 2000, 126(5):593-600.

22. Abdollahi-Fakhim S, Naderpoor M, Shahid N, Javadrashid R, Mashrab O, Ravaghi M. Assessment of adenoid size in children. Res J Biol Sci. 2008, 3(7):747-9.

23.Castellucci-Barbosa M, Knop LAH, Lessa MM, Araujo TM. Avaliação da radiografia cefalométrica lateral como meio de diagnóstico da hipertrofia de adenóide. R Dental Press Ortodon e Ortop Facial. 2009,14(4): 83-91.

24. Marchesan IQ, KrakauerLR.The importance of respiratory activity in myofunctional therapy. Int J Orofacial Myology. 1996, 22:23-7.

25. Ikino CMY, D‘Antonio WEPA, de la Cortina RAC, Lessa M, Castilho AM, Goto EY, Butugan O, Amaral TS. Teleradiologia lateral de crânio e radiografia de cavum: Estudo comparativo em crianças com obstrução nasal. Rev Bras Otorrinolaringol. 2000, 66(6):592-6. 